\title{
Carbon Capture Clustering: the Case for Coordinated Approaches to Address Freshwater Use Concerns
}

\author{
Byers, Edward A. ${ }^{1}$ Amezaga, Jaime M. ${ }^{1}$ and Hall, Jim W. ${ }^{2}$ \\ ${ }^{1}$ School of Civil Engineering \& Geosciences, Newcastle University, UK \\ ${ }^{2}$ Environmental Change Institute, University of Oxford, UK
}

\begin{abstract}
Carbon capture and storage (CCS) will be a key technology for reducing emissions from fossil-fuelled electricity generation. The UK is developing demonstration plants and UK Government strategy proposes the clustering of CCS facilities, having identified significant cost-savings from shared pipeline infrastructure. However, cooling water use from CCS power plants are almost double those of conventional plants. There are concerns about the volumes of freshwater used and vulnerability to low river flows, particularly in areas identified for CCS clusters. Two innovative approaches may reduce water use in CCS clusters by exploiting synergies with other infrastructures; district heating and municipal wastewater. Our analysis indicates that cooling water reductions from district heating may be feasible in the northwest, but less likely in Yorkshire. We also find that across the UK there are numerous, sufficiently large wastewater treatment plants capable of providing alternative cooling water sources for large power plants. Feasibility of these promising options will be highly contextual, require detailed analysis and may face economic and regulatory barriers. Historically, ad-hoc development of energy infrastructure has struggled to exploit such synergies, but may now be facilitated by the clustering of CCS facilities.
\end{abstract}

Keywords: Water-Energy Nexus, Cooling Water, Carbon Capture and Storage, Combined Heat and Power, Wastewater

\section{INTRODUCTION}

The societal challenge of reducing greenhouse gas (GHG) emissions to mitigate anthropogenic global warming has led to focussed research efforts on technological systems to sequester GHGs from fossil-fuelled electricity generation, known as carbon capture and storage (CCS). Thermoelectric generation (coal, gas, nuclear) currently accounts for $80 \%$ of global electricity production ${ }^{1}$ and the majority of this capacity is reliant on cooling water for safe and efficient operation. Recent studies across the world have highlighted concerns about the cooling water requirements for

International Energy Agency. IEA Energy Statistics - Eletcricity for World. (2009). at <http://www.iea.org/stats/electricitydata. asp?COUNTRY_CODE=29> 
fossil-fuelled electricity generation with carbon capture and storage. $2,3,4,5,6,7,8$

Whilst only in demonstration phases, carbon capture and storage systems appended to fossil-fuelled generation place parasitic loads on the power plant in order to sequester the carbon before it is emitted to the atmosphere. This results in not only a reduction in production efficiency but also in increased waste heat and hence cooling demands $8,9.9,10$ Three drivers make this a critical issue worth exploring further. Firstly, wide-scale deployment of CCS in global electricity production is integral to achieving the stabilisation of global average temperature increases below $4^{\circ} \mathrm{C}$, and particularly at $2^{\circ} \mathrm{C}^{6}$. Secondly, the impacts of climate change, population growth, urbanisation and rising affluence will likely increase industrial and agricultural demands and also water scarcity in many parts of the world. Thirdly, the increased water-intensity of CCS-enabled electricity production and the clustering of CCS facilities will compound the pressure on localised water resources. In this paper we elaborate on these pressures with a focus on CCS development in the UK and discuss two innovative opportunities to reduce freshwater requirements from CCS generation: the use of combined heat and power to reduce cooling demands and the use of wastewater as an alternative cooling water source.

\section{FUTURE DEMANDS FOR COOLING WATER FROM CARBON CAPTURE}
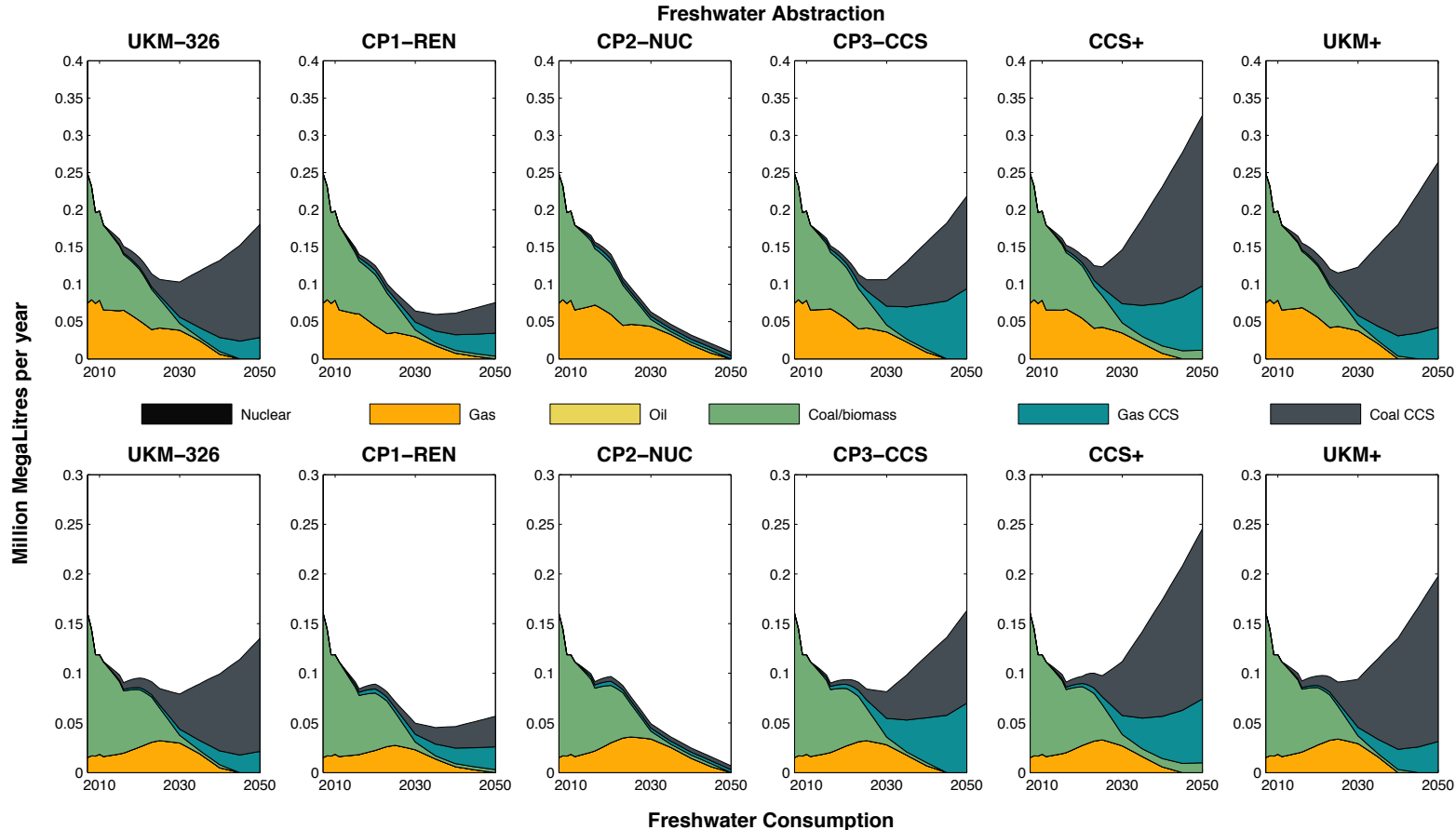

Figure 1. Abstraction and consumption of freshwater, split by generation technology for six energy pathways from 2007-2050. $(C C-B Y) 2$

The study by Byers, Hall and Amezaga² calculated the current and projected cooling water use of six low-carbon

2 Byers, E. A., Hall, J. W. \& Amezaga, J. M. Electricity generation and cooling water use: UK pathways to 2050. Glob. Environ. Chang. 25, 16-30 (2014).

3 Macknick, J., Sattler, S., Averyt, K., Clemmer, S. \& Rogers, J. The water implications of generating electricity: water use across the United States based on different electricity pathways through 2050. Environ. Res. Lett. 7, 045803 (2012).

4 Naughton, M., Darton, R. C. \& Fung, F. Could Climate Change Limit Water Availability for Coal-fired Electricity Generation with Carbon Capture and Storage? A UK Case Study. Energy Environ. 23, (2012).

5 Hadian, S. \& Madani, K. The Water Demand of Energy: Implications for Sustainable Energy Policy Development. Sustainability 5, 4674-4687 (2013).

6 World Energy Council. Water for Energy. (World Energy Council, 2010).

7 IEA. Technology Roadmap: Carbon capture and storage. Energy Technol. Perspect. (2013).

8 International Energy Agency. in World Energy Outlook 2012 (IEA, 2012).

9 Zhai, H., Rubin, E. S. \& Versteeg, P. L. Water use at pulverized coal power plants with postcombustion carbon capture and storage. Environ. Sci. Technol. 45, 2479-85 (2011).

10 Zhai, H. \& Rubin, E. S. Performance and cost of wet and dry cooling systems for pulverized coal power plants with and without carbon capture and storage. Energy Policy 38, 5653-5660 (2010). 
energy pathways from 2010 to 2050 for the UK. Four of the six pathways form the basis of the UK Government's 'Carbon Plan'11 with the aim of meeting the UK Climate Change Act 2008 targets for an $80 \%$ reduction in Greenhouse Gas emissions (on 1990 levels) by 2050.

Of the six pathways, those with high levels of CCS penetration (CP3-CCS, CCS+, UKM+) result in freshwater consumption in 2050 that exceed 2010 levels by 37-107\% (Figure 1). The research also reports the rise in consumptive freshwater-use intensity driven by the more water-intensive CCS generation. The trend is towards power stations that are, on average, twice as water-intensive as the current stock (Figure 2). The study also notes that up to 2025, freshwater use actually declines due to the EU Large Combustion Plant Directive and delays in the commercialisation of CCS. This trend only reverses from 2025 onwards as the penetration of CCS increases.

Similar results have been produced ${ }^{12},{ }^{13}$ using similar energy pathways that built on the work of Byers et al.., ${ }^{2}$ by disaggregating the demands on a regional basis. A large majority of elevated freshwater demands occur in regions with significant CCS capacity, namely the northwest, Thames and Yorkshire/Humber and East Midlands areas. This is expected to occur due to the clustering of CCS facilities in order to reduce the costs of pipeline infrastructure, as directed by the Department for Energy and Climate Change (DECC) CCS Roadmap ${ }^{14}$.

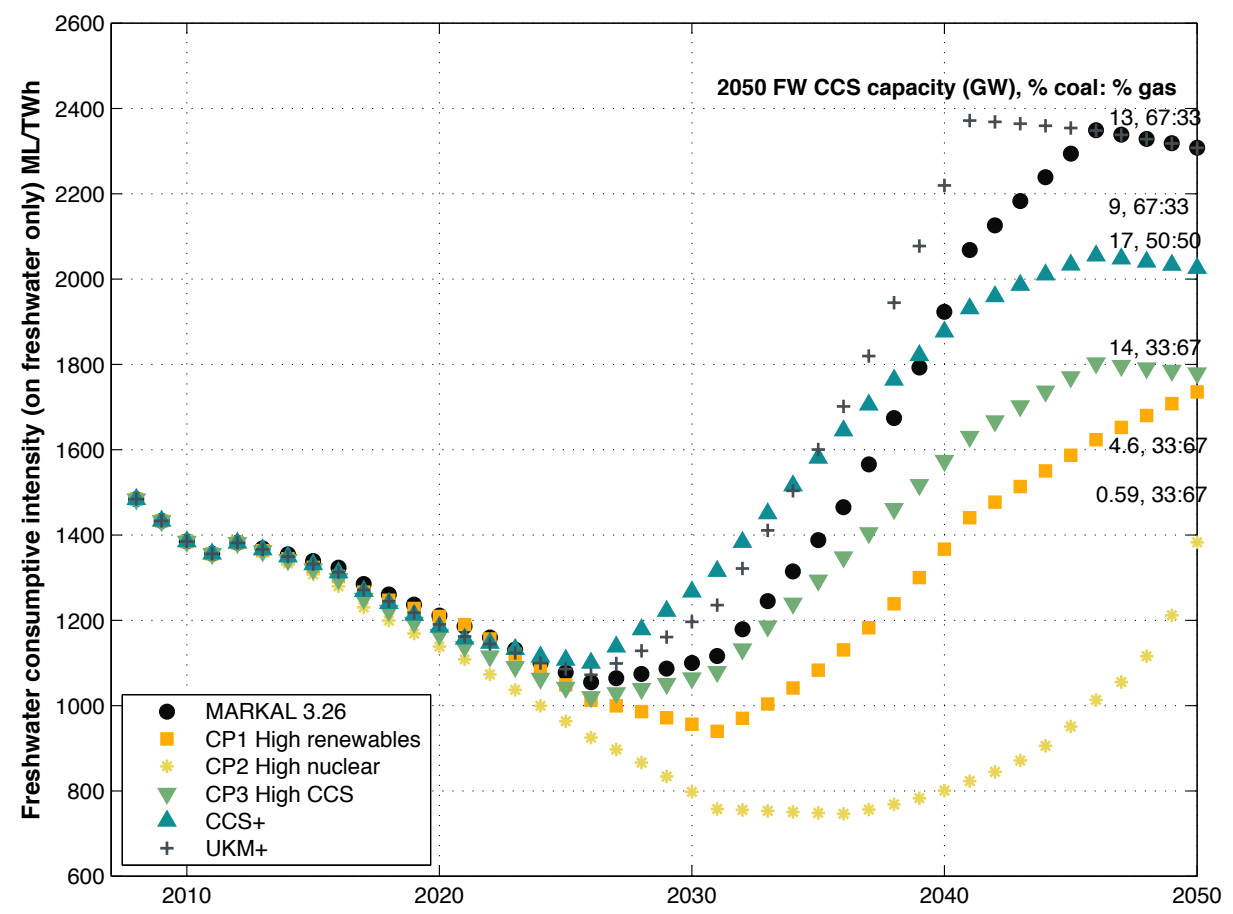

Figure 2. Average freshwater intensity (ML/GWh) of thermoelectric generation decreases due to closure of more inefficient plants under the LCPD, but then rises again with the introduction of CCS capacity from 2025 onwards. Pathways with more coal are more water intensive.

\section{BENEFITS AND CONCERNS OF CCS CLUSTERING}

The case for the clustering of CCS facilities is driven by a few interconnected issues: the legacy of power generation sites, industry and water availability; proximity to the coast and $\mathrm{CO}_{2}$ storage sites; and subsequently the economic advantages of clustering infrastructure. Potential clusters in the UK were identified in the government's CCS Roadmap, in Scotland, Yorkshire \& Humber, Teesside and near the East Irish Sea (the north west) given that

11 HM Government. The Carbon Plan: Delivering our low carbon future. (Department of Energy \& Climate Change, 2011).

12 Tran, M. et al. National infrastructure assessment: Analysis of options for infrastructure provision in Great Britain. (Environmental Change Institute, University of Oxford, UK, 2014).

13 Hall, J. W., Nicholls, R. J., Tran, M., Hickford, A. J. \& Otto, A. The Future of National Infrastructure: A System-of-Systems Approach. (Cambridge University Press, 2015).

14 DECC. CCS Roadmap. (Department of Energy \& Climate Change, 2012). 
concentrations of power generation and industry are also close to storage locations offshore ${ }^{14}$. Amongst other recommendations, the CCS Cost Reduction Task Force concludes that the costs of CCS can be reduced through investment in large $\mathrm{CO}_{2}$ clusters and investment in large shared pipelines ${ }^{15}$. From demonstration to more widescale development, it is estimated that transport and storage costs can be reduced by two-thirds when shared pipelines have high utilisation and clusters are supplying $\mathrm{CO}_{2}$ to clusters of storage sites. To date the identification of clusters has led to more coordinated work such as for the Thames estuary ${ }^{16}$, the Don Valley ${ }^{17}$ and the Tees Valley ${ }^{18}$ projects.

The size of these clusters is important in determining what potential impacts may arise. The E.ON Thames estuary cluster study identified 10 major power generation sites with total annual emissions potential of $27.9 \mathrm{MtCO}_{2} / \mathrm{yr}$, whilst $67 \%$ of the northeast's emissions could be captured from just 6 sites in the Tees valley. When evaluating the available water resources, the Environment Agency will need to consider carefully the aforementioned increased water-use intensity of CCS facilities, dependent on the proportion of emissions captured from the site. In the first stages of CCS development only $25-50 \%$ of emissions will be captured. However, this proportion will increase in the future, for both new and existing facilities. Hence, power plant operators may come across difficulties in obtaining further abstraction licences when seeking to expand the CCS facilities at a plant.

\section{INNOVATIONS FOR REDUCING THE WATER INTENSITY OF CCS CLUSTERS}

\section{Combined heat and power to reduce cooling demands}

Further use of combined heat and power (CHP) may be well suited to CCS clusters. CHP is the process of removing the waste heat from power generation and providing it for use by another user, usually domestic or industrial. The clustering of CHP plants with CCS facilities presents technical challenges such as the availability of space, but also synergistic opportunities. Industrial facilities can make use of waste heat, otherwise heat can be transported for district heating, with the costs shared amongst power stations. Such implementation however would require significant strategic direction and inclusion at the beginning of the design cycle. Uptake of district heating in the UK to date has been low compared to other parts of Europe, contributing less than $2 \%$ of heat demand. With the right conditions, including government incentives, it is thought this could contribute up to $14 \%^{19}{ }^{18}$. Subsequently, DECC have developed a "national heat map for England" which shows the intensity of heating demand across the country ${ }^{20},{ }^{21}$. Inspection indicates that the use of CHP on CCS could be economical in the northwest, but less likely in the Yorkshire, Humber, east Midlands and north east areas (Figure 2).

The seasonal variation of heat demand (unless industrial) complicates economic implementation of CHP in the UK. Nonetheless it is not hard to imagine that a well designed industrial ecosystem could turn the threat of localised highintensity water demands into a reliable source of heat that shares infrastructure costs not just for CO2 pipelines but also heat transport.

15 The Crown Estate, Carbon Capture \& Storage Association \& DECC. CCS Cost Reduction Taskforce: Final Report. (CCS Cost Reduction Taskforce, 2013).

16 E.ON UK. Capturing carbon, tackling climate change: A vision for a CCS cluster in the South East. (2009).

17 Powerfuel Power Ltd. Environmental Statement - Section 36 Application. Hatf. Power Park (Heaton Planning, 2008).

18 ONE North East \& Amec. Engineering Design and Capture Technologies for Carbon Capture and Storage in the Tees Valley. (ONE North East, 2010).

19 Davies, G. \& Woods, P. The potential and costs of district heating networks. A Rep. to Dep. Energy Clim. Chang. (2009).

20 DECC. National Heat Map. (2014). at <http://tools.decc.gov.uk/nationalheatmap/\#>

21 DECC. Heat networks. Increasing use low carbon Technol. (2014). at <https://www.gov.uk/government/policies/increasing-theuse-of-low-carbon-technologies/supporting-pages/heat-networks> 


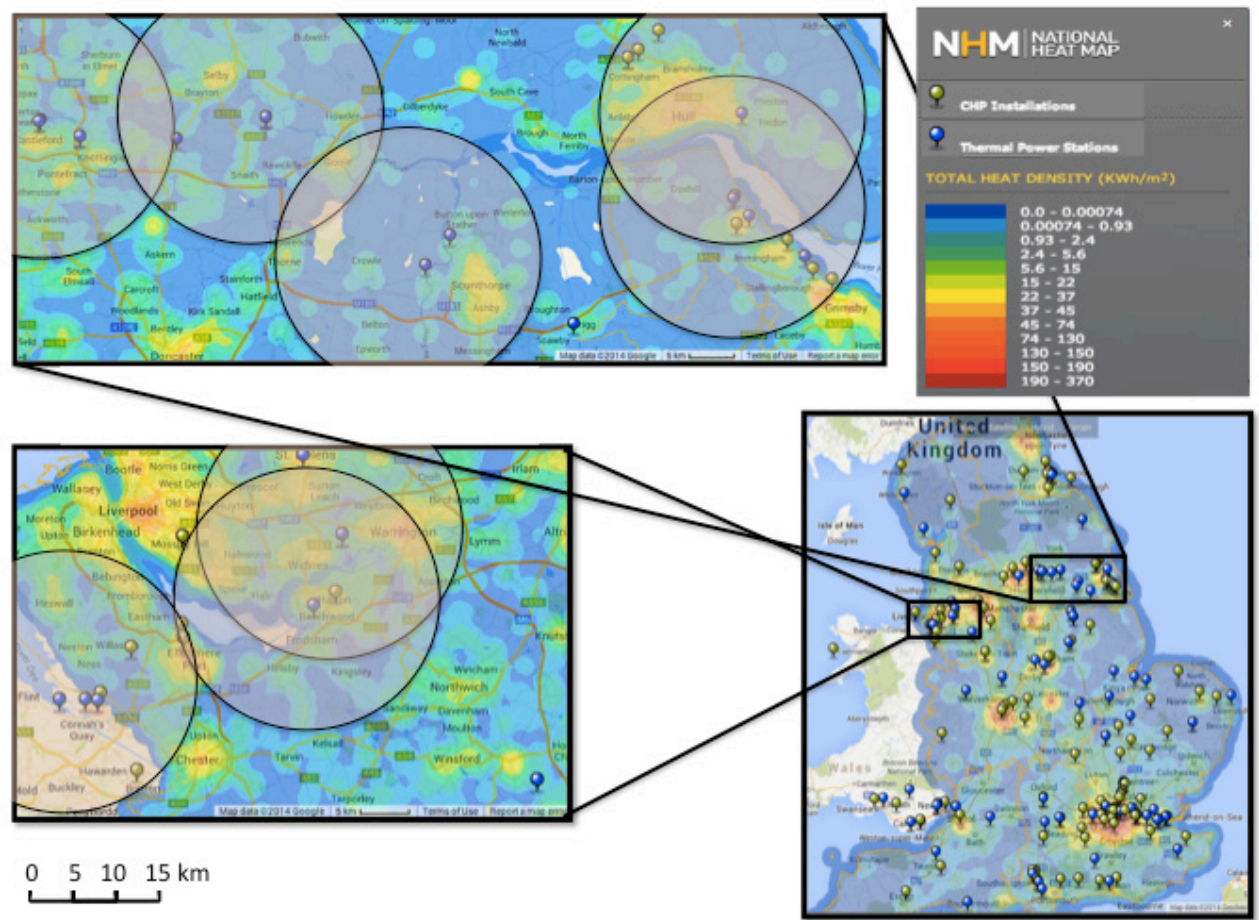

Figure 2. Screenshots of the National Heat Map from DECC ${ }^{19}$. Blue markers indicate current power stations, green markers are current CHP schemes. The heat demand intensity is indicated by the shaded colours. Shaded circles indicate radii of $15 \mathrm{~km}$ from power stations from which heat could be economically transported.

\section{Wastewater as an alternative cooling water source}

The second opportunity is the use of treated wastewater as a cooling water source in closed loop wet cooling towers. As of 2007, over 50 power plants in the U.S. used wastewater, mostly for cooling but also boiler feed water in some cases ${ }^{21}$. There is a growing body of technical research in this area coming from the U.S. that has been pilot and field-tested 22,23,24,25,26,27,28,29. Municipal wastewater is even used for cooling at the Palo Verde nuclear power plant, the largest in the U.S., providing a reliable cooling water source in Arizona whilst increasing revenue for the local water company ${ }^{30}$. In the UK, both the 363 MW coal (soon to be mothballed) and 834 MW CCGT Uskmouth power stations also pioneer the use of treated wastewater for their boiler feed water, but not for cooling ${ }^{31}$.

Further challenges of using wastewater include contaminants and nutrients in the water, condenser tube fouling,

22 Veil, J. A. Use of reclaimed water for power plant cooling. (Argonne National Laboratory, 2007).

23 EPRI. Produced Water Resources, Wet-Surface Air Cooling, and WARMF Decision Support Framework. Progr. Technol. Innov. Water Resour. Thermoelectr. Power (EPRI, Palo Alto, CA and USDOE, Morgantown, WV, 2006).

24 NETL. Power Demand Options in Regions of Water Stress and Future Carbon Management. Thermoelectr. Power Plant Water Demands Using Altern. Water Supplies (National Energy Technology Laboratory, USDOE, 2010).

25 Donovan, J. J. et al. WRI 50: Strategies for Cooling Electric Generating Facilities Utilizing Mine Water : Technical and Economic Feasibility Project. (U.S. Department of Energy, 2004).

26 Arthur, J. D. Internet Based, GIS Catalog of Non-Traditional Sources of Cooling water for Use at America's Coal-Fired Power Plants. (National Energy Technology Laboratory, USDOE, 2011).

27 Dzombak, D. A., Vidic, R. D. \& Landis, A. E. Use of Treated Municipal Wastewater as Power Plant Cooling System Makeup Water: Tertiary Treatment versus Expanded Chemical Regimen for Recirculating Water Quality. (National Energy Technology Laboratory, USDOE, 2012).

28 Walker, M. E. et al. Utilization of municipal wastewater for cooling in thermoelectric power plants: Evaluation of the combined cost of makeup water treatment and increased condenser fouling. Energy 60, 139-147 (2013).

29 Ciferno, J., Aljoe, W. W. \& Dzombak, D. A. Tertiary Treatment Versus Expanded Chemical Regimen for Recirculating Water Quality Management. Use Treat. Munic. Wastewater as Power Plant Cool. Syst. Makeup Water (National Energy Technology Laboratory, USDOE, 2009).

30 Rodriguez, D. J., Delgado, A., Delaquil, P. \& Sohns, A. Thirsty Energy. Water Pap. (World Bank, 2013).

31 Power Engineering. Siemens hands over 834 MW Uskmouth CCGT in UK to DONG Energy. Power Eng. (2010). 
increased risk of Legionnaire's disease, proximity to wastewater sources and increasing competition for sources of treated wastewater ${ }^{27}$. In some UK rivers, wastewater makes up a considerable proportion of the river flows and maintains the environmental integrity. Reducing municipal wastewater returns could also increase the occurrence of low flows. Conversely this may be welcomed by wastewater treatment companies who are finding it increasingly difficult to meet effluent quality regulations in low flows due to lack of dilution. A further non-technical barrier could be Ofwat, the economic regulator for the water sector, who have prevented investment in areas outside the core business, such as renewables electricity generation ${ }^{32} 32$.

Successful integration between wastewater and electricity production will be highly contextual and location specific. Given the right incentives, wastewater for cooling presents an innovative opportunity for the UK's wastewater system, which in some places is over 100 years old. We estimate that a sewage treatment works capable of serving one million people at full capacity is of sufficient size to provide a reliable cooling water flow of approximately $1 \mathrm{~m}^{3} / \mathrm{s}$ assuming that $60 \%$ of the supply volume is discharged. This would be sufficient for large power stations operating at full load: an 800 $\mathrm{MW}_{\mathrm{e}}$ coal+CCS plant, or almost a 2,000 MW gas CCGT+CCS plant, if using closed loop wet tower cooling. For current capacity without CCS, the potential would be a further 90\% higher. There are approximately 25 wastewater treatment plants with this capacity of 1 million people, a further 90 that can serve 300,000 people, and even four plants with capacity in the order of 3-4 million people. More detailed studies evaluating technological, geographic economic and regulatory feasibility, as has been done in the U.S., ${ }^{25,33}$ are highly recommended for the UK.

\section{CONCLUSIONS}

Current policy, technologic, economic and geographic circumstances suggest that the clustering of CCS-enabled power stations is likely to occur in the UK. The increased water-use intensity of CCS technology coupled with this clustering also presents concerns for both the water and energy security of the UK. High cooling water demands from the sector will be more vulnerable, and may possibly contribute, to localised water scarcity which can be expected to increase with both population growth and climate change.

The two suggestions of using combined heat and power to utilise waste heat and using wastewater as a cooling water source are both technically feasible and already implemented in a variety of contexts across the world. The barriers to their implementation in the UK lie within wider constraints of economic viability and the need for better integration of power stations within their wider environments. Both opportunities would require early involvement at the design stage and probably public-private partnerships for local integration. The nature of CCS infrastructure development in clusters also requires similar planning and implementation, thus consideration of the potential to use $\mathrm{CHP}$ or wastewater is recommended.

Preliminary analysis suggests that the potential feasibility of CHP systems is greater in the northwest than the Humber/East Midlands regions, due to higher concentration of heating demands and closer proximity of the power stations. This is likely to also be the case for wastewater availability. However, industrial developments in the Humber area may provide concentrated demands and sources of heat and wastewater, respectively. If clustered CCS developments occur in these two areas, as is expected, sharp increases in the demands for cooling water will occur. Greater use of CHP and wastewater for cooling has the potential to reduce the pressures on freshwater resources, and thus the feasibility of these opportunities should be investigated in detail, at the earliest stage possible.

32 Watson, J. \& Rai, N. Governance interdependencies between the water \& electricity sectors. (2013).

33 Stillwell, A. S. \& Webber, M. E. Geographic, technologic, and economic analysis of using reclaimed water for thermoelectric power plant cooling. Environ. Sci. Technol. 48, 4588-95 (2014). 